\title{
Editorial
}

\section{Rational Use of Antidepressant Drugs}

\author{
Giovanni A. Fava ${ }^{a, b}$

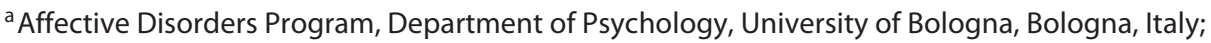 \\ ${ }^{b}$ Department of Psychiatry, State University of New York at Buffalo, Buffalo, N.Y., USA
}

A rational use of drugs depends on the balance of potential benefits and adverse effects applied to the individual patient [1]. A problem in achieving such a balance derives from the different sources of information that need to be integrated. Guidelines tend to place emphasis on systematic reviews and meta-analyses of randomized controlled trials that are uniquely geared to detecting benefits [1]. Observational studies tend to be considered to have less validity, despite evidence to call such a view into question [2]. The appraisal of adverse effects relies primarily on observational studies and data from routine clinical practice and may not emerge from randomized controlled trials, unless these effects occur early in treatment and are specifically investigated [1].

The use of antidepressant drugs (AD) exemplifies the discrepancy between different sources of information. Adverse events that may be subsumed under the rubric of tolerance [3] and that may be overlooked by guidelines, such as those of the American Psychiatric Association [4], will be critically examined. Clinical decisions concerned with the provision of knowledge to the individual patient need to be placed within the framework of risk (the likelihood of poor outcomes of an index disorder if the therapy is withheld), responsiveness to the treatment option, and vulnerability to the adverse effects of treatment [5]. How such a framework may affect prescription practices in mood and anxiety disorders will be discussed.

\section{KARGER}

E-Mail karger@karger.com

www.karger.com/pps

\section{Tolerance and Its Different Expressions}

Several clinical phenomena have been documented during $\mathrm{AD}$ treatment (loss of $\mathrm{AD}$ efficacy, tachyphylaxis, resistance, paradoxical effects, switching to a bipolar course and withdrawal reactions).

\section{Loss of AD Efficacy}

The prevalence of a return of depressive symptoms during maintenance $\mathrm{AD}$ treatment was $9-57 \%$ in published trials [6], pointing to an occurrence of tolerance phenomena during $\mathrm{AD}$ treatment [7-10]. This increases with the duration of treatment; in a meta-analysis of maintenance treatment studies, the risk of relapse progressively increased from 23\% within 1 year over $34 \%$ within 2 years to $45 \%$ within 3 years [10]. The term 'tachyphylaxis' (the progressive decrease in response to a given dose after repetitive administration of a pharmacologically or physiologically active substance) has also been used to designate the relapse during maintenance treatment or clinical deterioration characterized by symptoms such as apathy and fatigue $[11,12]$.

The effectiveness of a drug increase in relapse during maintenance treatment of major depression was assessed in a controlled study concerned with fluoxetine administered at $20 \mathrm{mg}$ daily or $90 \mathrm{mg}$ weekly [13]; $57 \%$ of the patients on the daily dosage and $72 \%$ on the weekly dosage (c) 2014 S. Karger AG, Basel

0033-3190/14/0834-0197\$39.50/0
Giovanni A. Fava, MD

Department of Psychology, University of Bologna Viale Berti Pichat 5

IT-40127 Bologna (Italy)

E-Mail giovanniandrea.fava@unibo.it 
responded to the dose increase. One patient out of 5 who initially responded to the dose increase relapsed again during the 25-week trial [13]. It is conceivable that more relapses would have been observed with a continuation of the trial, as was found to be the case in recurrent depression [14]. Similar findings were obtained in a placebocontrolled trial of duloxetine [15]. Interestingly, in two small controlled studies $[16,17]$, psychotherapy without modifying the drug regimen was significantly more effective than a dose increase in yielding a persistent remission in depressed patients who displayed a loss of clinical effect during maintenance treatment with $\mathrm{AD}$.

\section{Resistance to $A D$}

There is considerable confusion over the term 'resistance' in mood disorders, since it is applied to either depressive illness (an episode which does not respond to drugs or psychotherapy) or to lack of response to a previously effective pharmacological treatment when it is started again after a drug-free period. The former use is the one which is prevalent, but also the latter is worth clinical attention. Indeed, a lack of response after rechallenge was found to occur in a quarter of cases in an observational study [18]. Prior exposures to $\mathrm{AD}$ have also been found to induce a resistance to AD different from those that were administered during the first trials $[18,19]$. Resistance was analyzed in a study on 122 patients who, after initially responding to fluoxetine, were assigned to placebo. About half of the patients relapsed. Thirty-eight percent of the patients either did not respond or initially responded but again relapsed after reinitiation of the medication [20].

The data available thus indicate that when a drug treatment is reinstituted, a patient may not respond to the same $\mathrm{AD}$ which had initially improved the depressive symptoms. The prevalence of this type of resistance varies. Patients who respond to a reinstitution of the same AD may display a subsequent loss of therapeutic effect [20]. This suggests that resistance and loss of efficacy may be related and share a common mechanism.

\section{Paradoxical Effects}

In 1968, di Mascio et al. [21] studied the effects of imipramine on individuals with varying levels of depression, using a double-blind placebo-controlled procedure. They found an increase in depression levels after the use of imipramine in subjects with the lowest scores of depression. This early study suggested the possibility that when depressive symptoms are minimal, AD may do more harm than good in certain individuals. The use of
AD may be associated not only with the return of depressive symptoms during maintenance treatment but also with the appearance of new symptoms and an exacerbation of the baseline clinical picture (paradoxical effects). Improvement may result from $\mathrm{AD}$ discontinuation [8]. An occurrence of paradoxical effects was reported in double-blind placebo-controlled trials with fluoxetine [22] and sertraline [23]. El-Mallakh et al. [24] have introduced the concept of $\mathrm{AD}$-induced tardive dysphoria that may be reversed by tapering or discontinuing the $\mathrm{AD}$.

Fux et al. [25] observed an emergence of depressive symptoms in 7 of 80 patients (9\%) during treatment of panic disorder with fluvoxamine. These patients had no history of mood disorder, and no symptoms of depression were present before the treatment with fluvoxamine. The symptoms abated when fluvoxamine was discontinued and tricyclic antidepressants (TCA) or clonazepam were prescribed, and they reappeared when fluoxetine was administered. Similar issues were raised by the use of TCA in anxiety disorders [26]. Raja [27] described 9 cases with an excellent response to a first treatment with $\mathrm{AD}$, followed by a loss of efficacy, resistance and worsening with subsequent treatment. He documented how the three clinical phenomena described above may be interrelated and part of the same syndrome.

\section{Switching to Bipolar Disorder}

Treatment with AD has been associated with mania or other forms of excessive behavioral activation [28]. These responses may reveal an unrecognized bipolar illness or may be drug induced, since they may also occur in allegedly unipolar patients. In the early 1980s, Kukopulos et al. [29] observed how treatment with AD may contribute to changes in the course from unipolar to bipolar illness. They deserve credit for having raised the issue that $\mathrm{AD}$ induced mania may not simply be a temporary and fully reversible phenomenon but may trigger complex biochemical mechanisms of illness deterioration. His group [30] also outlined the association of $\mathrm{AD}$, whether they be TCA or selective serotonin reuptake inhibitors (SSRI), with mixed depression, defined as depression with excitatory symptoms. Bader and Dunner [31] retrospectively reviewed the records of 146 patients with treatment-resistant depression. Among these, 16 had experienced new hypomanic episodes during treatment with AD. Since only 1 patient had reported a family history of bipolar disorder, these episodes seemed to be specifically induced by the exposure to $\mathrm{AD}$.

A systematic review and meta-analysis concerned with excessive mood elevation and behavioral activation in 
children and adolescents disclosed that the rates of excessive arousal-activation were very high both in anxiety (13.8\%) and depression (9.8\%) with $\mathrm{AD}$, and much lower with placebos (5.2 and 1.1\%, respectively) [32]. Furthermore, the incidence of manic or hypomanic manifestations was much higher than that in comparable reports involving anxious adults, and similar to the rates reported for depressed adults, all treated with $\mathrm{AD}$ [32]. Hence, in anxiety disorders, the risk of developing behavioral activation may occur also with the use of $\mathrm{AD}$, particularly in younger patients.

\section{Withdrawal Reactions}

Withdrawal symptoms following the discontinuation of $\mathrm{AD}$ treatment were soon recognized after the introduction of these drugs [33]. They have been described for any type of $\mathrm{AD}$, but particularly for SSRI, venlafaxine and duloxetine $[8,34-35]$. They have generally been defined as 'discontinuation syndromes', with the aim to avoid any hint of a potential for dependence from SSRI that may affect marketing. The withdrawal syndrome is characterized by a broad range of somatic symptoms such as headache, dizziness, fatigue, diminished appetite, sleep disturbances (vivid dreams and insomnia), somnolence, flu-like symptoms, nausea and vomiting $[34,35]$. Less common physical symptoms include myalgias, Parkinsonism, balance difficulties and cardiac arrhythmias. Psychological symptoms may ensue as well, such as agitation, anxiety, panic attacks, dysphoria, confusion and worsening of mood $[34,35]$. Discontinuation symptoms typically appear within 3 days of stopping $\mathrm{AD}$ medication or initiating a medication taper. Untreated symptoms may be mild and resolve spontaneously within 1-3 weeks; in other cases, they may persist for months or even years [36,37], leading to what has been defined as 'persistent post-withdrawal disorder' [38].

It is a common belief that withdrawal symptoms can be avoided by slow tapering. However, this does not appear to be the case, as was found in a randomized controlled trial comparing rapid and slow tapering [39] and in an observational study [36]. The discontinuation of $\mathrm{AD}$ may also trigger hypomania or mania, despite concurrent mood-stabilizing treatment [40]. The syndrome may be self-limiting, may abate with a reinstitution of $\mathrm{AD}$ or may require specific antimanic treatment. Mood elevation may also occur with an $\mathrm{AD}$ dose decrease [41], and patients who failed to respond to mood stabilizers in combination with $\mathrm{AD}$ may improve after the discontinuation of $\mathrm{AD}$ [42]. Withdrawal symptoms are likely to be misunderstood as indicators of impending relapse and may lead to a reinstitution of treatment.

\section{The Oppositional Model of Tolerance}

The clinical phenomena that have been described may be unified under the oppositional model of tolerance [3, 8]. According to this model, continued drug treatment may recruit processes that oppose the initial acute effects of a drug. This may explain the loss of efficacy. It may also propel an illness to a more malignant and treatment-unresponsive course, as with a bipolar course or paradoxical reactions (paradoxical effects). When drug treatment ends, oppositional processes may operate for some time, resulting in the appearance of withdrawal symptoms, an increased vulnerability to relapse, or resistance if treatment is reinstituted. These phenomena should be kept in mind when weighing the potential benefits and harms of the institution of an AD therapy. There is evidence that the risk of relapse after $\mathrm{AD}$ discontinuation can be interpreted according to the oppositional model of tolerance $[8,43]$, supporting the hypothesis that, in certain cases, long-term treatment with $\mathrm{AD}$ may increase chronicity and sensitize to subsequent episodes [3].

\section{Treatment of a Major Depressive Episode}

If we want to place the benefits and harms of $\mathrm{AD}$ in the context of risk, responsiveness and vulnerability [5] and choose the most appropriate approach to an individual patient, a number of assessment strategies need to supplement the diagnosis of major depressive disorder.

\section{Assessment}

The primary indication for the use of $\mathrm{AD}$ is the treatment of a major depressive disorder. Their overall effectiveness has been inflated by selective reporting of positive trials [44]. Further, AD are unlikely to be better than placebo in mild or minor depression $[45,46]$. Even if a certain degree of severity is established, the clinical threshold provided by diagnostic criteria can be lowered by the presence of anxiety disturbances; anxious depression is less likely to respond to $\mathrm{AD}$ than nonanxious depression [47]. In the setting of comorbidity - that is, in the majority of cases there is the possibility of placing particular emphasis on specific symptoms, instead of simply counting them [48]. For instance, the characteristics that are most predictive of a positive response to $\mathrm{AD}$ (anorexia, weight loss, middle and late insomnia and psychomotor disturbance) can be given more emphasis than other symptoms. Another important issue is concerned with the primary/secondary distinction of depression that is based on chronology [48]. Secondary depressions are unlikely to fully remit with the 
use of a single therapeutic agent [49]. Finally, when the severity of a major depressive episode is established, attention should be given to features that may be suggestive of a bipolar course or family history.

An issue that is frequently neglected is the fact that patients who present with a major depressive episode are often already consuming $\mathrm{AD}$. In this case, is the episode related to a loss of clinical effect or to resistance after the reinitiation of treatment? The term 'iatrogenic comorbidity' refers to the lasting effects that previous treatments may entail, well beyond their time of administration [50]. Such effects may affect subsequent treatment. Staging may be a very helpful strategy in the setting of a depressive disorder to indicate its longitudinal course or history of treatment resistance [51].

\section{When to Use $A D$}

The magnitude of benefit from AD medication compared with placebo increases with the severity of depression [46]. If a patient suffers from severe depression, there is little doubt that pharmacotherapy may yield substantial benefits, even though, of course, the response may vary from patient to patient. However, if symptoms of mild or moderate intensity are present, the benefits may be minimal or nonexistent [46]. The neglect of the clinical phenomena related to tolerance may urge a clinician to give it a trial, a position that does not reflect the evidence in the field on the effectiveness of placebo, that is, the likelihood that depressive symptoms remit with nonspecific ingredients [52]. An alternative is to postpone prescribing an $\mathrm{AD}$ and to see the patient again after a couple of weeks. This may be particularly important in the setting of medical disease, when depression may subside with the improvement of the medical condition and/or discharge from the hospital [53]. If the symptoms have improved to a certain degree, the need of $\mathrm{AD}$ treatment may be low; in case of the persistence (or, at times, of worsening) of symptoms, the use of $\mathrm{AD}$ appears to be more justified and worth pursuing.

\section{The Choice of an $A D$}

The various types of $\mathrm{AD}$ may be substantially equivalent in efficacy in the average case of depression $[4,54$, 55]. Such an assumption, however, may apply to the first episode of depression in a patient who has never been treated with AD. Even in this case there are important issues to be considered. TCA, despite their side effects, may be more efficacious than SSRI in melancholic depression [56]. The efficacy and tolerability of venlafaxine and duloxetine have been overstated and their use as first-line treatment is now questionable [57].
Differences in the occurrence of adverse effects may exist with second-generation $\mathrm{AD}$ [55]. However, if a patient has already been treated with $\mathrm{AD}$, the choice has to take into account the treatment history of the patient [58], that is, his/her iatrogenic comorbidity [50], and whether he/she displayed a loss of clinical efficacy, resistance, withdrawal, paradoxical reactions or behavioral activation with regard to a specific agent. Unfortunately, there is very little literature that has correlated the response to $\mathrm{AD}$ to the prior treatment history [58]. There are insufficient data to indicate that certain types of $\mathrm{AD}$ may induce tolerance more easily than other types, even though this is an issue that deserves to be explored [59]. It is reasonable to assume that if a patient experienced tolerance to a certain class of drugs, that class should probably be avoided, but this remains to be adequately tested [8]

\section{Psychotherapeutic Management}

Each therapeutic act may be seen as a result of multiple ingredients that may be specific or nonspecific [60]; it is not simply due to the net sum of benefits and adverse effects [1], but to their variable interaction [60].

Psychotherapeutic management (application of psychological understanding to the management and rehabilitation of an individual patient, including establishing a therapeutic relationship, identifying current problems with specific assessment procedures and encouraging self-therapy) is often confused with formal psychotherapy. For instance, when filling a drug prescription, adding another prescription with simple indications in terms of scheduling and exposure homework may encourage lifestyle modifications that may have an impact on the drug effect [61]. Expectations, preferences, motivation, ambivalence about medications and readiness to change are all characteristics that may affect treatment outcome [60].

\section{Duration of Treatment}

The time to recovery is very individualized, but at least 6 months of drug treatment appear to be necessary for most patients to reach a satisfactory level [62]. This time can be shortened to 3 months before tapering if a sequential combination of pharmacotherapy and psychotherapy is employed [49]. Indeed, the benefits of applying psychotherapeutic strategies after $\mathrm{AD}$ treatment have become maximal when drug discontinuation by slow tapering is achieved [63].

There is a tendency to protract drug treatment for long periods of time, with the assumption that it may be protective against relapse. In a meta-analysis, Kaymaz et al. [64] have found that $\mathrm{AD}$ reduce the relapse risk in the mainte- 
nance phase. However, patients with multiple depressive episodes experienced significantly less benefit in relapse prevention during the $\mathrm{AD}$ maintenance phase than those with a single episode. These findings suggest that, in patients with recurrent depression, relapse is difficult to control by AD only. Viguera et al. [65] analyzed 27 studies with variable lengths of $\mathrm{AD}$ treatment and follow-up upon drug discontinuation. When one more study [12] was included, the risk of postdiscontinuation relapse was nearly significantly greater after long treatment following recovery from an index episode of major depression [7].

The length of the first AD treatment was studied in relation to relapse in a sample of 9,243 patients treated with SSRI [66]. The subjects were followed up for 5 years and divided into early discontinuers (who discontinued AD within 6 months), continuing users (who received AD for 6-12 months) and persistent users (who were treated with $\mathrm{AD}$ for more than 12 months). No differences were found in time to recurrence between the patients who were treated for 6 months and those treated for 6-12 months. Those who received AD for more than 1 year showed a $23 \%$ higher risk of experiencing a second episode than the early discontinuers. These results were also confirmed in a subsequent study reporting no differences in risk of relapse between early discontinuers and continuing AD users [67].

Another negative aspect of long-term $\mathrm{AD}$ treatment is concerned with the serious and bothersome side effects that may ensue with SSRI, such as high rates of sexual dysfunction, bleeding (in particular gastrointestinal), weight gain, risk of fracture and osteoporosis, and hyponatremia [68]. Such effects may be more pronounced in the setting of medical disease, where also drug interactions should be considered $[53,69]$.

These considerations suggest that treatment with $\mathrm{AD}$ should be as short as possible, even though it is difficult to shorten it to less than 3 months before tapering is performed [49]. When the patient stops improving, this is probably the time to start tapering the drug at the slowest possible pace, with decrements every 2 weeks [49]. In patients for whom tapering does not appear to be feasible (about $20 \%$ of cases in sequential studies), treatment should be protracted, but this option should be pursued only if alternatives have failed or cannot be performed [49].

\section{Treatment-Resistant Depression}

Very seldom, a discrimination of the clinical phenomena related to tolerance is performed when assessing treatment resistance in depression [70]. The Sequenced Treatment Alternatives to Relieve Depression (STAR*D) Study
[71] may illustrate the importance of taking manifestations of tolerance into consideration. The aim of the trial was to apply the best pharmacological strategies for obtaining remission in major depression. Patients who did not recover were submitted to four sequential steps involving switching, augmentation and combination strategies, based on the available literature. The results were rather disappointing. The cumulative rate of remission after 4 sequential steps was 67\%, and if sustained recovery (taking into account relapse rates while on treatment) was considered, the cumulative rate was $43 \%$. This means that the strenuous efforts after step 1 (open treatment with citalopram) yielded an additional $6 \%$ of sustained recovery. Even though each step of the trial was carefully conceived to increase the likelihood of response in patients who did not remit, the remission rates decreased after each treatment step [71]. The rates of relapse increased after each treatment step in the patients who achieved remission. Further, intolerance (dropouts for any reason during the first 4 weeks, or side effects afterwards) increased after each treatment step.

Many of the STAR*D findings can be interpreted in light of oppositional tolerance [8]: pharmacological manipulations, either by switching or augmentation (steps 1 and 2), may propel a depressive illness into a refractory phase, characterized by low remission, high relapse and high intolerance (steps 3 and 4). Augmentation strategies should probably be avoided altogether and switching should follow a clinical reasoning based on a patient's treatment history and episodes of tolerance [58].

\section{AD in Anxiety Disorders}

In the past years, a progressive change in prescribing pattern from benzodiazepines (BDZ) to second-generation $\mathrm{AD}$ has been observed in anxiety disorders [72]. In a recent systematic review [73], no consistent evidence emerged supporting the advantage of using $\mathrm{AD}$ over $\mathrm{BDZ}$ in treating anxiety disorders. Indeed, BDZ showed fewer treatment withdrawals and adverse events than $A D$. In panic disorder with and without agoraphobia, BDZ treatment was more effective than $\mathrm{AD}$ in reducing the number of panic attacks [73].

A major drive in the shift from $\mathrm{BDZ}$ to $\mathrm{AD}$ in anxiety disorders was the risk of dependence with BDZ. However, in due course after their introduction, similar, if not more pronounced, problems occurred with most of the newer $\mathrm{AD}$, as reviewed above. Withdrawal reactions and postwithdrawal syndromes may ensue, despite slow tapering, with both types of drugs. The various types of BDZ may 
differ in their side effect profile: rebound anxiety, withdrawal syndromes and dependence appear to be greater with short-to-intermediate elimination half-life agents than with those with long half-lives [74]. Memory impairment appears to be related to lipid solubility [74]. The disadvantages entailed by the use of BDZ such as clonazepam may be remarkably reduced compared with $\mathrm{AD}$ such as paroxetine [73]. Further, the tolerance entailed by $\mathrm{AD}$ may induce a higher vulnerability to depression in patients who were never depressed before [8] as well as to hypomania/mania, particularly in younger subjects [32]. One should be particularly concerned about young patients who start taking $\mathrm{AD}$ for anxiety disorders and prolong this treatment indefinitely without undergoing any form of psychotherapy. What will be the long-term outcome of their disturbances? Will tolerance develop and trigger deterioration and refractoriness? In the setting of a major depressive episode coexisting with an anxiety disorder, the use of $\mathrm{AD}$ may be justified. In all other cases, treatment with AD should be carefully considered, unless psychotherapeutic alternatives are not available or effective or BDZ fail to provide adequate relief.

In a recent trial [75], 297 patients with social anxiety disorder were treated with sertraline; the rates of remission (13\%) and response (32\%) were very low. Nonresponders were randomized to sertraline plus clonazepam, a switch to venlafaxine or to sertraline plus placebo. The addition of clonazepam was found to yield significant advantages over other strategies. The authors' conclusion, supported by an accompanying editorial [76], was that clonazepam augmentation provides benefits for sertraline nonresponders in social anxiety disorder [75]. What was not discussed is the obvious inappropriateness of sertraline as first-line treatment due to its very low response and remission rates that are very unlikely to be better than those of placebo. Further, once sertraline is introduced, one is left with an iatrogenic comorbidity that is likely to have a negative effect on cognitive behavioral therapy, as was found to be the case in a placebo-controlled study [77]. Why not treating those patients with clonazepam only from the beginning? This needs to be tested in a controlled trial comparing clonazepam, sertraline and placebo in social anxiety disorder.

\section{Conclusions}

A rational use of $\mathrm{AD}$ that incorporates all potential benefits and harms consists in targeting their application to only the most severe and persistent cases of depression, limiting their use to the shortest possible duration and reducing their utilization in anxiety disorders (unless a major depressive disorder is present or other treatments have been ineffective). These suggestions may seem to be radically different from current guidelines such as those of the American Psychiatric Association [4], but they reflect the weighing of risk, responsiveness and vulnerability [5] that should be applied to the use of $\mathrm{AD}$ in each individual case. A selection of treatment according to evidence-based medicine relies primarily on randomized controlled trials and meta-analyses $[1,2]$. However, this evidence applies to the 'average' patient and ignores the fact that customary taxonomy does not include patterns of symptoms, the severity of an illness, effects of comorbid conditions, the timing of phenomena, the rate of progression of an illness, responses to previous treatments and other clinical distinctions that demarcate major prognostic and therapeutic differences among patients who otherwise seem to be deceptively similar since they share the same diagnosis [48].

Indeed, the American Psychiatric Association guideline for the treatment of patients with major depressive disorder states that the ultimate recommendation regarding a particular clinical procedure or treatment plan must be made by the psychiatrist in light of the clinical data, the psychiatric evaluation, and the diagnostic and treatment options available. Such recommendations should incorporate the patient's personal and socio-cultural preferences and values in order to enhance the therapeutic alliance, adherence to treatment, and treatment outcomes' [4, p. 9].

$\mathrm{AD}$ were developed and found to be effective in the treatment of severe depression, but the better tolerability of newer AD has stretched their original indications [78, 79]. Their use has been prolonged to maintenance and prevention of relapse of depression, and has been extended to anxiety disorders. A large body of randomized controlled trials concerned with $\mathrm{AD}$ is available, but there is a pressing need of research encompassing risks, responsiveness and vulnerability [5].

$\mathrm{AD}$ are important and potentially lifesaving drugs if the proper indications are endorsed. However, currently, the prescribing physician is driven by an overestimated consideration of potential benefits, little attention to the likelihood of responsiveness and neglect of potential vulnerabilities to the adverse effects of treatment.

\section{Disclosure Statement}

The author has no conflict of interest to declare. 


\section{References}

1 Vanderbroucke JP, Psaty BM: Benefits and risks of drug treatments: how to combine the best evidence on benefits with the best data about adverse effects. JAMA 2008;300:24172419.

$>2$ Concato J, Shah N, Horwitz RI: Randomized, controlled trials, observational studies, and the hierarchy of research designs. N Engl J Med 2000;342;1887-1892.

-3 Fava GA: Can long-term treatment with antidepressant drugs worsen the course of depression? J Clin Psychiatry 2003;64:123-133.

4 American Psychiatric Association: Practice guideline for the treatment of patients with major depressive disorder, ed 3. Am J Psychiatry 2010;167(suppl):1-118.

$\checkmark 5$ Richardson WS, Doster LM: Comorbidity and multimorbidity need to be placed in the context of a framework of risk, responsiveness, and vulnerability. J Clin Epidemiol 2014; 67:244-246.

6 Byrne SE, Rothschild AJ: Loss of antidepressant efficacy during maintenance therapy. J Clin Psychiatry 1998;59:279-288.

$\checkmark 7$ Baldessarini RJ, Ghaemi SN, Viguera AC: Tolerance in antidepressant treatment. Psychother Psychosom 2002;71:177-179.

-8 Fava GA, Offidani E: The mechanisms of tolerance in antidepressant action. Prog Neuropsychopharmacol Biol Psychiatry 2011;35: 1593-1602.

9 McGrath PJ, Stewart JW, Quitkin FM, Chen Y, Alpert JE, Nierenberg AA, Fava M, Cheng J, Petkova E: Predictors of relapse in a prospective study of fluoxetine treatment of major depression. Am J Psychiatry 2006;163: 1542-1548.

10 Williams N, Simpson AN, Simpson K, Nahas $\mathrm{Z}$ : Relapse rates with long-term antidepressant drug therapy: a meta-analysis. Hum Psychopharmacol 2009;24:401-408.

11 Rothschild AJ: The Rothschild Scale for Antidepressant Tachyphylaxis: reliability and validity. Compr Psychiatry 2008;49:508-513.

-12 Solomon DA, Leon AC, Mueller TI, Coryell W, Teres JJ, Posternak MA, Judd LL, Endicott J, Keller MB: Tachyphylaxis in unipolar major depressive disorder. J Clin Psychiatry 2005; 66:283-290.

13 Schmidt ME, Fava M, Zhang S, Gonzales J, Raute NJ, Judge R: Treatment approaches to major depressive disorder relapse. Part I. Dose increase. Psychother Psychosom 2002; 71:190-194.

14 Franchini L, Rossini S, Bongiorno F, Spagnolo C, Smeraldi E, Zanardi R: Will a second prophylactic treatment with a higher dosage of the same antidepressant either prevent or delay new depressive episodes? Psychiatry Res 2000;96:81-85.

-15 Fava M, Detke MJ, Balestrieri M, Wang F, Raskin J, Perahia D: Management of depression relapse: re-initiation of duloxetine treatment or dose increase. J Psychiatry Res 2006; 40:328-336.
16 Fabbri S, Fava GA, Rafanelli C, Tomba E: Family intervention approach to loss of clinical effect during long-term antidepressant treatment: a pilot study. J Clin Psychiatry 2007;68:1348-1351.

17 Fava GA, Ruini C, Rafanelli C, Grandi S: Cognitive behavior approach to loss of clinical effect during long-term antidepressant treatment: a pilot study. Am J Psychiatry 2002;159: 2094-2095.

18 Leykin Y, Amsterdam JD, DeRubeis RJ, Gallop R, Shelton RC, Hollon SD: Progressive resistance to a selective serotonin reuptake inhibitor but not to cognitive therapy in the treatment of major depression. J Consult Clin Psychol 2007;75:267-276.

19 Amsterdam JD, Williams D, Michelson D, Adler LA, Dunner DL, Nierenberg AA, Reimherr FW, Schatzberg AF: Tachyphylaxis after repeated antidepressant drug exposure in patients with recurrent major depressive disorder. Neuropsychobiology 2009;59:227-233.

20 Fava M, Schmidt ME, Zhang S, Gonzales J, Raute NJ, Judge R: Treatment approaches to major depressive disorder relapse. Part II. Reinitiation of antidepressant treatment. Psychother Psychosom 2002;71:195-199.

21 di Mascio A, Meyer RE, Stifler L: Effects of imipramine on individuals varying in level of depression. Am J Psychiatry 1968;127:55-58.

$\checkmark 22$ Cusin C, Fava M, Amsterdam JD, Quitkin FM, Reimherr FW, Beasley CM Jr, Rosenbaum JF, Perlis RH: Early symptomatic worsening during treatment with fluoxetine in major depressive disorder: prevalence and implications. J Clin Psychiatry 2007;68:5257.

23 Harvey AT, Silkey BS, Kornstein SG, Clary CM: Acute worsening of chronic depression during a double-blind, randomized clinical trial of antidepressant efficacy: differences by sex and menopausal status. J Clin Psychiatry 2007;68:951-958.

24 El-Mallakh RS, Gao Y, Briscoe BT, Roberts JR: Antidepressant induced tardive dysphoria. Psychother Psychosom 2011;80:57-59.

25 Fux M, Taub M, Zohar J: Emergence of depressive symptoms during treatment for panic disorder with specific 5-hydroxytryptophan reuptake inhibitors. Acta Psychiatr Scand 1993;88:235-237.

26 Noyes R, Garvey HJ, Cook BL: Follow-up study of patients with panic disorder and agoraphobia with panic attacks treated with tricyclic antidepressants. J Affect Disord 1989; 16:249-257.

27 Raja M: Delayed loss of efficacy and depressogenic action of antidepressants. J Clin Psychopharmacol 2009;29:612-614.

28 Tondo L, Vázquez G, Baldessarini RJ: Mania associated with antidepressant treatment: comprehensive meta-analytic review. Acta Psychiatr Scand 2010;121:404-414.
29 Kukopulos A, Reginaldi D, Laddomada P, Floris G, Serra G, Tondo L: Course of the manic-depressive cycle and changes caused by treatment. Pharmakopsychiatr Neuropsychopharmakol 1980;13:156-167.

30 Sani G, Napoletano F, Vohringer PA, Sullivan M, Simonetti A, Koukopoulos A, Girardi P, Ghaemi N: Mixed depression: clinical features and predictors of its onset associated with antidepressant use. Psychother Psychosom 2014;83:213-221.

31 Bader CD, Dunner DL: Antidepressant-induced hypomania in treatment-resistant depression. J Psychiatr Pract 2007;13:233-237.

32 Offidani E, Fava GA, Tomba E, Baldessarini RJ: Excessive mood elevation and behavioral activation with antidepressant treatment of juvenile depressive and anxiety disorders. Psychother Psychosom 2013;82:132-141.

33 Kramer JC, Klein DF, Fink M: Withdrawal symptoms following discontinuation of imipramine therapy. Am J Psychiatry 1961;118: 549-550.

34 Lejoyeux M, Adès J, Mourad I, Solomon J, Dilsaver S: Antidepressant withdrawal syndrome: recognition, prevention and management. CNS Drugs 1996;5:278-292.

35 Baldwin DS, Montgomery SA, Nil R, Lader M: Discontinuation symptoms in depression and anxiety disorders. Int J Neuropsychopharmacol 2007;10:73-84.

36 Fava GA, Bernardi M, Tomba E, Rafanelli C: Effects of gradual discontinuation of selective serotonin reuptake inhibitors in panic disorder with agoraphobia. Int J Neuropsychopharmacol 2007;10:835-838.

>37 Belaise C, Gatti A, Chouinard VA, Chouinard G: Patient online report of selective serotonin reuptake inhibitor-induced persistent postwithdrawal anxiety and mood disorders. Psychother Psychosom 2012;81:386-388.

38 Belaise C, Gatti A, Chouinard VA, Chouinard G: Persistent post-withdrawal disorders induced by paroxetine, a selective serotonin reuptake inhibitor, and treated with specific cognitive behavioral therapy. Psychother Psychosom 2014;83:247-248.

39 Tint A, Haddad PM, Anderson IM: The effect of antidepressant tapering on the incidence of discontinuation symptoms: a randomised study. J Psychopharmacol 2008;22:330-332.

40 Andrade C: Antidepressant-withdrawal mania. J Clin Psychiatry 2004;15:987-993.

41 Corral M, Sivertz K, Jones BD: Transient mood elevation associated with antidepressant drug decrease. Can J Psychiatry 1987;32: 764-767.

42 Sharma V: Loss of response to antidepressants and subsequent refractoriness. J Affect Disord 2001;64:99-106.

43 Andrews PW, Kornstein SG, Halberstadt LJ, Gardner CO, Neale MC: Blue again: perturbational effects of antidepressants suggest monoaminergic homeostasis in major depression. Front Psychol 2011;2:159. 
44 Turner EH, Matthews AM, Linardatos E, Tell RA, Rosenthal R: Selective publication of antidepressants trails and its influence on apparent efficacy. N Engl J Med 2008;358:252-260.

45 Paykel ES, Hollyman JA, Freeling P, Sedgwick P: Predictors of therapeutic benefit from amitriptyline in mild depression. J Affect Disord 1988;14:83-95.

-46 Fournier JC, DeRubeis RJ, Hollon SD, Dimidjian S, Amsterdam JD, Shelton RC, Fawcett J: Antidepressant drug effects and depression severity. JAMA 2010;303:47-53.

-47 Fava M, Rush J, Alpert JE, Balasubramani GK, Wisniewski SR, Carmin CN, Biggs MM, Zisook S, Leuchter A, Howland R, Warden D, Trivedi MH: Difference in treatment outcome in outpatients with anxious versus nonanxious depression. Am J Psychiatry 2008; 165:342-351.

-48 Fava GA, Rafanelli R, Tomba E: The clinical process in psychiatry: a clinimetric approach. J Clin Psychiatry 2012;73:173-184.

49 Fava GA, Tomba E: New modalities of assessment and treatment planning in depression. CNS Drugs 2010;24:453-465.

50 Fava GA, Tomba E, Tossani E: Innovative trends in the design of therapeutic trials in psychopharmacology and psychotherapy. Prog Neuropsychopharmacol Biol Psychiatry 2013;40:306-311.

-51 Cosci F, Fava GA: Staging of mental disorders: systematic review. Psychother Psychosom 2013;82:20-34.

52 Rutherford B, Roose SP: A model of placebo response in antidepressant clinical trials. Am J Psychiatry 2013;170:723-733.

53 Rackley S, Bostwick JM: Depression in medically ill patients. Psychiatr Clin North Am 2012;35:231-247.

54 Malhi GS, Hitching R, Berk M, Boyce P, Porter R, Fritz K: Pharmacological management of unipolar depression. Acta Psychiatr Scand 2013;127(suppl 443):6-23.

55 Gartlehner G, Hansen RA, Morgan LC, Thaler K, Lux L, van Noord M, Mager U, Thieda P, Gaynes BN, Wilkins T, Strobelberger M, Lyoid S, Reichenpfader U, Lohr KN: Comparative benefits and harms of second-generation antidepressants for treating major depressive disorder. Ann Intern Med 2011;155: 772-785.

56 Perry PJ: Pharmacotherapy for major depression with melancholic features. J Affect Disord 1996;39:1-6.
57 Schueler YB, Koesters M, Wieseler B, Grouven U, Kromp M, Kerekes MF, Kreis J, Kaiser T, Becker T, Weinmann S: A systematic review of duloxetine and venlafaxine in major depression, including unpublished data. Acta Psychiatr Scand 2011;123:247-265.

58 Tomba E: Nowhere patients. Psychother Psychosom 2012;81:69-72.

59 Posternak MA, Zimmerman M: Dual reuptake inhibitors incur lower rates of tachyphylaxis than selective serotonin reuptake inhibitors. J Clin Psychiatry 2005;66:704-707.

60 Mintz DL, Flynn DF: How (not what) to prescribe: nonpharmacologic aspects of psychopharmacology. Psychiatr Clin North Am 2012;35:143-163.

61 Tomba E, Fava GA: Treatment selection in depression: the role of clinical judgment. Psychiatr Clin North Am 2012;35:87-98.

62 Keller MB, Lavori PW, Mueller TI, Endicott J, Coryell W, Hirschfeld RMA, Shea T: Time to recovery, chronicity, and levels of psychopathology in major depression. Arch Gen Psychiatry 1992;49:809-816.

63 Guidi J, Fava GA, Fava M, Papakostas GI: Efficacy of the sequential integration of psychotherapy and pharmacotherapy in major depressive disorder. Psychol Med 2011;41:321331.

64 Kaymaz N, van Os J, Loonen AJ, Nolen WA: Evidence that patients with single versus recurrent depressive episodes are differentially sensitive to treatment discontinuation: a meta-analysis of placebo-controlled randomized trials. J Clin Psychiatry 2008;69:1423-1436.

65 Viguera AC, Baldessarini RJ, Friedberg J: Discontinuing antidepressant treatment in major depression. Harv Rev Psychiatry 1998;5:293306.

66 Gardarsdottir H, van Geffen EC, Stolker JJ, Egberts TC, Heerdink ER: Does the length of the first antidepressant treatment episode influence risk and time to a second episode? J Clin Psychopharmacol 2009;29:69-72.

67 Gardarsdottir H, Egberts TC, Stolker JJ, Heerdink ER: Duration of antidepressant drug treatment and its influence on risk of relapse/recurrence: immortal and neglected time bias. Am J Epidemiol 2009;170:280-285.
68 Moret C, Isaac M, Briley M: Problems associated with long-term treatment with selective serotonin reuptake inhibitors. J Psychopharmacol 2009;23:967-974.

69 Fava GA, Sonino N: Depression associated with medical illness. CNS Drugs 1996;5:175189.

70 Carvalho AF, Berk M, Hyphantis TN, McIntyre RS: The integrative management of treatment-resistant depression. Psychother Psychosom 2014;83:70-88.

71 Rush AJ, Trivedi MH, Wisniewski SR, Nierenberg AA, Stewart JW, Warden D, Niederehe G, Thase ME, Lavori PW, Lebowitz BD, McGrath PJ, Rosenbaum JF, Sackeim HA, Kupfer DJ, Luther J, Fava M: Acute and longer-term outcomes in depressed outpatients requiring one or several treatment steps: a STAR*D report. Am J Psychiatry 2006;163: 1905-1917.

72 Baldwin DS, Allgulander C, Bandelow B, Ferre F, Pallanti S: An international survey of reported prescribing practice in the treatment of patients with generalised anxiety disorder. World J Biol Psychiatry 2012;13:510-516.

73 Offidani E, Guidi J, Tomba E, Fava GA: Efficacy and tolerability of benzodiazepines versus antidepressants in anxiety disorders. Psychother Psychosom 2013;82:355-362.

74 Chouinard G: Issues in the clinical use of benzodiazepines: potency, withdrawal and rebound. J Clin Psychiatry 2004;65(suppl 5):712.

75 Pollack MH, van Ameringen M, Simon N, Worthinton JW, Hoge EA, Keshaviah A, Stein MB: A double-blind randomized controlled trial of augmentation and switch strategies for refractory social anxiety disorder. Am J Psychiatry 2014;171:44-53.

76 Roy-Byrne P: Treatment in nonresponsive patients with social anxiety: back to the future with benzodiazepines. Am J Psychiatry 2014; 171:1-4.

-77 Haug TT, Blomhoff S, Hellstrom K, Holme I, Humble M, Madsbu HP, Wold JE: Exposure therapy and sertraline in social phobia. Br J Psychiatry 2003;182:312-318.

78 Fava GA: Long-term treatment with antidepressant drugs: the spectacular achievements of propaganda. Psychother Psychosom 2002; 71:127-132.

-79 Ghaemi NS, Vohringer PA, Whitham EA: Antidepressants from a public health perspective: re-examining effectiveness, suicide, and carcinogenicity. Acta Psychiatr Scand 2013;127:89-93. 